\title{
Identification of Skeletal Deformities in Far Eastern Catfish, Silurus asotus under Indoor Aquaculture Condition
}

\author{
Won Seok Yang ${ }^{1}$, Hyun Woo Gil ${ }^{1}$, Gwang Yeol Yoo ${ }^{2}$ and ${ }^{\dagger}$ In-Seok Park ${ }^{1}$ \\ ${ }^{1}$ Division of Marine Bioscience, College of Ocean Science and Technology, \\ Korea Maritime and Ocean University, Busan 606-791, Korea \\ ${ }^{2}$ The Province of Chungcheongnam-do Fisheries Research Institute, Boryeng 355-851, Korea
}

\begin{abstract}
For the 2 years of farming, at the indoor circulating aquaculture system, four kinds of skeletal deformities were found among 60 Far Eastern catfish, Silurus asotus. Deformities saw jawbone's luxation, abnormality of upper lip and malocclusion. Spinal deformity was most fatal deformities with low weight and small length. Jawbone's luxation had 1 maxilla and 2 mandibles. Abnormality of upper lip had just lip was back over. Malocclusion's left maxilla and right maxilla were not balanced. This experiment was any deformities in this species through the deformity can grasp how it affects.
\end{abstract}

Key words : Abnormality, Far Eastern catfish, Skeletal deformity, Silurus asotus

\section{INTRODUCTION}

Far Eastern catfish, Silurus asotus is classified Siluriformes and Siluridae (Park et al., 2004). The fish is warm water fish so it inhabits $20 \sim 27^{\circ} \mathrm{C}$ and it lives soft ground. And the fish is nocturnal so it active night and it is carnivorous fish so it mostly predates not only crustaceans but also aquatic animals. Far Eastern catfish grow about $20 \sim 50 \mathrm{~cm}$ per a year. The fish live all of Korea rivers, and international habitat is Japan, China and Taiwan. They are delicious and highly nutritious so utilized by edible fish (Park et al., 2004).

To develop aquaculture technique of Far Eastern catfish in Korea, biological techniques were studied such as temperature dependent mitotic cycle, triploid, gynogenetic diploid, breeding and rearing, spermatozoa structure, inducing ovulation, and karyokinesis in embryos (Choi et al., 1992; Kwon et al., 1996; Kwon et al., 1998; Kim et al., 2001; Im et al., 2000, 2001, 2002; Park \& Im, 2001). Besides, occurrences of abnormal fishes were studied in previous researches (Nguyen et al., 2008; Lijalad \& Powell, 2009; Roo et al., 2009; Boglino et al., 2011; Haga et al., 2011). Decreasing abnormal fishes is very important for optimum production. Therefore, deformity of Far Eastern catfish must be studied for development of aquaculture technique.

Deformities are observed all of organisms, and it justly appears to fish. Fish have various deformities, representatively skeletal deformities. Skeletal deformities were observed such as gilthead sea bream, Sparus aurata, Senegalese sole, Solea senegalensis, and Atlantic salmon, Salmo salar (Gavaia et al., 2009; Georgakopoulou et al., 2010; Boglino et al., 2011). Until now, the deformity of fish were studied about

\footnotetext{
Manuscript received 4 May 2015, Received in revised form 15 May 2015, Accepted 30 May 2015

† Corresponding author : In-Seok Park, Division of Marine Bioscience, College of Ocean Science and Technology, Korea Maritime and Ocean University, Busan 606-791, Korea. Tel. : +82-51-410-4321, Fax : +82-51-405-4322, E-mail : ispark@kmou.ac.kr

This is an Open Access article distributed under the terms of the Creative Commons Attribution Non-Commercial License (http:// creativecommons.org/licenses/by-nc/3.0) which permits unrestricted non-commercial use, distribution, and reproduction in any medium, provided the original work is properly cited.
} 
body shape, jaw deformity, vertebral deformity and skeletal deformity (Nguyen et al., 2008; Lijalad \& Powell, 2009; Boglino et al., 2011; Haga et al., 2011).

Skeletal deformities have many risks for fish, such as swimming performance, feed efficiency, limit of the feed, infectious disease and lethality (Andrades et al., 1996; Imsland et al., 2006; Le Vay et al., 2007; Lijalad \& Powell, 2009; Puvanendran et al., 2009). Furthermore, deformities make concern from fish welfare (Ashley, 2007).

Deformities were found in indoor rearing conditions in 2 years, this study began to determine what type of deformity is found. So, this experiment measured dimension of morphometric characteristic (Park et al., 2004), length, weight, gonadosomatic index (GSI), hepatosomatic index (HSI) and viscera index (VI). In addition, this study observed Far Eastern catfish's skeletal structure using X-ray system.

\section{MATERIALS AND METHODS}

\section{Environmental condition and diets}

In July 2012, using this experimental fish, 60 Far Eastern catfish, Silurus asotus were produced of seeds and sampling at the Fishery Genetics and Breeding Sciences Laboratory, Korea Maritime and Ocean University, Busan, Korea. Deformity was chosen to have cosmetic differences.

A Far Eastern catfish's tank that was a circulation filter water tank was under fluorescent light (1,000 lux) conditions. The light was on from 6:00 to 18:00. So, environmental condition was kept temperature, $\mathrm{pH}$, DO (dissolved oxygen), photoperiod, ammonia, nitric acid, nitrous acid and conductivity (Table 1). Water was changed fresh water once a week.

Assorted feed was made by Chenhajeil Feed ${ }^{\odot}$ (Daejeon, Korea). Feed composed following: Table 2. It was given ad libidum twice a day (9:00 and 18:00), by hand.

\section{Measurements}

In August 2014, Far Eastern catfish were stopped feeding
Table 1. Environmental rearing condition for Far Eastern catfish, Silurus asotus in this experiment*

\begin{tabular}{cc}
\hline \hline Test parameters & Condition \\
\hline Temperature $\left({ }^{\circ} \mathrm{C}\right)$ & $26 \pm 0.5$ \\
$\mathrm{pH}$ & $7.1 \pm 0.65$ \\
DO (dissolved oxygen; $\mathrm{mg} / \mathrm{L} ;$ & 7.6 \\
saturated concentration in $\left.26^{\circ} \mathrm{C}\right)$ & \\
Photoperiod (Fluorescence light : & $12: 12$ \\
dark; hour) & 0.01 \\
Ammonia $(\mathrm{ppm})$ & $1.8 \pm 0.14$ \\
Nitric acid $(\mathrm{ppm})$ & 0.01 \\
Nitrous acid $(\mathrm{ppm})$ & 238 \\
Conductivity $(u \mathrm{~s} / \mathrm{cm})$ &
\end{tabular}

${ }^{*}$ Test parameters were analyzed at 1 month interval during 2 years. The lux of fluorescence lights that used in this experiment were 1,000 lux. Temperature, $\mathrm{pH}$, dissolved oxygen and salinity were measured using an oxygen measurement electrode and a multi-data logger system (Oxyguard, Denmark). Ammonia, nitric acid, nitrous acid and conductivity were measured using spectrophotometer (DR2800, HACH, Loveland, Colorado, USA). The values are means of triplicate groups $(n=20)$.

on the day before study. After Far Eastern catfish samples were killed by overdosing with clove oil (Sigma, USA). They were taken pictured at above, side and head under copystand (Polaroid Dongwon Co., Korea). After taken picture, measured standard length $(L s)$ were measured as $\mathrm{cm}$ unit with ruler and body weight, gonad weight, liver weight and intestine weight were measured as $\mathrm{g}$ unit with electric balance (g; SHIMADZU AW320, Japan). Gonadosomatic index (GSI), hepatosomatic weight (HSI), and viscera index (VI) were calculated as GSI = (gonad weight/body weight $)$ $\times 100, \mathrm{HSI}=($ liver weight/body weight $) \times 100$, and VI $=$ (intestine weight/body weight) $\times 100$.

\section{Morphometric characteristics}

After analysis, Far Eastern catfish were fixed 1 day by $10 \%$ formalin, the day after changed new $10 \%$ formalin 
Table 3. Dimensions of morphometric characteristic used in this experiment ${ }^{*}$

\section{Dimensions}

Standard length

Direct distance between the anterior edge of the lower lip and the anterior insertion of the dorsal fin

Direct distance between the posterior insertion of the dorsal fin and the most posterior in lateral line

Horizontal distance between the most posterior in lateral line and the anterior insertion of the anal fin

Horizontal distance between the anterior edge of the lower lip and the anterior insertion of the ventral fin

Horizontal distance between the anterior edge of the lower lip and the origin of the pectoral fin

HALOP

Direct distance between the anterior edge of the most anterior middle point of operculum and the most posterior aspect of operculum

Direct distance between the anterior edge of the upper lip and the most posterior aspect of operculum

DAUPO

Direct distance between the anterior edge of the lower lip and the anterior insertion of the dorsal fin

DALAD

Caudal peduncle height

Body depth at the anterior insertion of the anal fin

BDAA

Body depth at the midpoint of the anal fin base

BDMA

Head width between the origin of the pectoral fins

HWOP

Head length between the anterior edge of the upper lip and the midpoint of head width

HL

Horizontal distance between the right end of lip and the left end of lip

HARL

Direct distance between the midpoint of head width and the right (left) maxilla barbel

DAHR(L)B

Direct distance between the midpoint of head width and the right (left) side of upper lip (the elongated point of first nostril)

Direct distance between the midpoint of head width and the right (left) side of lower lip (the elongated point of first nostril)

*Each dimension is demonstrated in Fig. 1 (Modified from Park et al., 2004).

jawbone's luxation, abnormality of upper lip, and malocclusion; Tables 4 and 5, Figs. 2 and 3) of deformity in Far Eastern catfish, Silurus asotus. The samples of standard length in other deformities, except for spinal deformity, were similar to normal sample, and the sample of spinal deformity had large odds between them (Table 4). Spinal deformity was so small that the weight was light in comparison with others. The abnormal rates of each group were 1/60 (1.6\%) and GSI, and HSI and VI made no odds. Therefore, other deformities, except for spinal deformity, did not influence on growth and production of eggs.

Normal samples had long and straight anal fin; however, spinal curvature had short anal fin (Fig. 2). Also, normal sample's tail fin was dropped, but spinal curvature was up and was seen to be connected with anal fin. Furthermore, tail was stubby. This skeletal structure indicated that the body was relatively round than normal sample, so it had fin spine upper. From spinal deformity, significant differences were found; DPDPL/Ls (62.8), HPLAA/Ls (44.1), and $\mathrm{CH} / L s$ (2.4) were smaller than others, and BDMA/BDAA (83.6) was larger $(P>0.05$; Table 5). This means that DPDPL, HPLAA, and CH were relatively long about $L s$, and BDMA was larger than others $(P>0.05)$. In X-ray (Fig. 3), normal sample has straight vertebra, short maxilla, and long mandible. In contrast, deformities are different. Spinal deformity does not have straight vertebra and the tail fin spine is pointing up.

As shown in Fig. 2, normal sample has a short maxilla 
Table 4. Comparative analysis of standard length, body weight, abnormal rate, gonadosomatic index (GSI), hepatosomatic index (HSI) and viscera index (VI) for each type of skeletal deformity in Far Eastern catfish, Silurus asotus ${ }^{* 1}$

\begin{tabular}{|c|c|c|c|c|c|c|}
\hline & \multirow{2}{*}{$\begin{array}{c}\text { Total samples } \\
\quad(n=60)\end{array}$} & \multirow{2}{*}{$\begin{array}{l}\text { Normal samples } \\
\qquad(n=56)\end{array}$} & \multicolumn{4}{|c|}{ Types of normal and skeletal deformity ${ }^{* 2}$} \\
\hline & & & $\mathrm{S}(n=1)$ & $\mathrm{J}(n=1)$ & $\mathrm{U}(n=1)$ & $\mathrm{M}(n=1)$ \\
\hline Standard length (mm) & $461 \pm 8.2$ & $461 \pm 8.2$ & 182.2 & 454.5 & 463.9 & 441.3 \\
\hline Body weight (g) & $341 \pm 9.8$ & $341 \pm 9.8$ & 122.4 & 354.1 & 367.2 & 349.1 \\
\hline Abnormal rate $(\%)$ & $4 / 60(6.5)$ & $0 / 56(0.0)$ & $1 / 60(1.6)$ & $1 / 60(1.6)$ & $1 / 60(1.6)$ & $1 / 60(1.6)$ \\
\hline $\mathrm{GSI}^{* 3}$ & $6.5 \pm 1.27$ & $6.5 \pm 1.00$ & 6.4 & 6.9 & 6.1 & 6.6 \\
\hline $\mathrm{HSI}^{*}$ & $3.2 \pm 1.54$ & $3.3 \pm 0.86$ & 3.0 & 3.4 & 3.9 & 3.1 \\
\hline $\mathrm{VI}^{* 5}$ & $5.1 \pm 1.41$ & $5.0 \pm 0.79$ & 4.8 & 4.8 & 4.9 & 4.1 \\
\hline
\end{tabular}

${ }^{{ }^{*} 1}$ The values of normal group are means $\pm \mathrm{SD}(n=20)$ of triplicate groups. ${ }^{{ }^{2}} \mathrm{~S}$ : spinal curvature; J: The luxation of jawbone; $\mathrm{U}$ : abnormality of upper lip; and M: malocclusion. ${ }^{* 3}$ Gonadosomatic index $(\mathrm{GSI})=($ gonad weight/body weight $) \times 100$.

${ }^{* 4}$ Hepatosomatic index $(\mathrm{HSI})=($ liver weight/body weight $) \times 100 .{ }^{* 5}$ Viscera index $(\mathrm{VI})=($ intestine weight/body weight $) \times 100$.

and a long mandible. However, jaw deformity has a long maxilla and short mandibles. It has a small and asymmetric head, and the eyes are protruded. So, only the maxilla can be observed when viewing from above. Furthermore, jaw deformity has 2 mandibles when saw side: outer side of mandible and inner side of mandible. Inner side of mandible is seen as a lump. As shown in Table 5, differences in the jaw deformity are DAAPO/Ls (16.8), DALAD/Ls (14.1), and HARL/HWOP (70.8). DAAPO and DALAD were so short that the data were too small $(P>0.05)$. Furthermore, HARL was too small to show low data $(P>0.05)$. In this deformity, standard length was too short, so DAAPO/Ls and $\mathrm{DALAD} / L s$ (14.1) were calculated to be low. Furthermore, this saw head had one flexion, so HARL/HWOP was calculated to be low. For the deformity in the saw side, there were three jawbones, and the inner mandible was connected to grill bones. Head bone was short and unstable, and saw gill arch (Fig. 3).

One has lip that is higher, and the right lip is shorter than the left lip (Fig. 2). The right lip was back over, so it saw inner. From the upper lip deformity, DAHLB \& DAHRB and DAHLU \& DAHRU were not in balance, so it made a difference $(P>0.05$; Table 5). DAHLB/DAHRB and DAHLU/DAHRU at about 100 were normal, but it

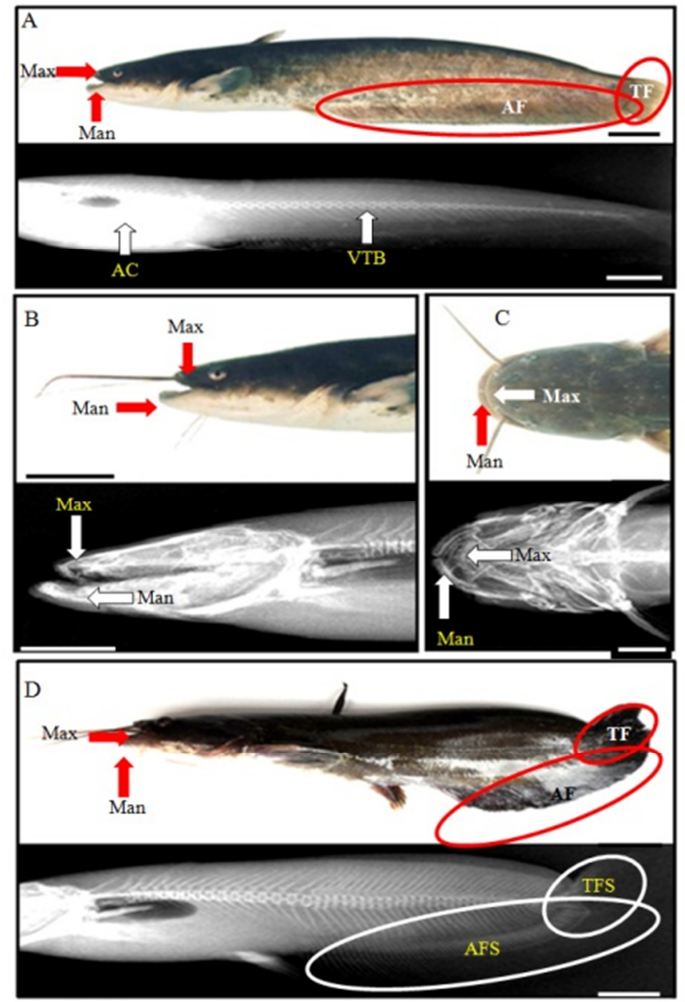

Fig. 2. The lateral and the dorsal views and X-ray pictures of normal and skeletal deformity group in Far Eastern catfish, Silurus asotus (upper: external morphology; lower: X-ray picture). A: the whole body of normal sample; B: head region in normal sample; $\mathrm{C}$ : head region in normal sample; and $\mathrm{D}$ : spinal curvature. AC: abdominal cavity; AF: anal fin; AFS: anal fin spine; Man: mandible; Max: maxilla; TF: tail fin; TFS: tail fin spine; and VTB: vertebra. Bars are $5 \mathrm{~cm}$. 
Table 5. Means and standard deviations for external morphometric trait of normal and skeletal deformity group in Far Eastern catfish, Silurus asotus ${ }^{* 1}$

\begin{tabular}{|c|c|c|c|c|c|}
\hline \multirow{2}{*}{$\begin{array}{l}\text { Morphometric } \\
\text { dimension (\%) }\end{array}$} & \multirow{2}{*}{$\begin{array}{l}\text { Normal samples } \\
\qquad(n=56)\end{array}$} & \multicolumn{4}{|c|}{ Types of skeletal deformity $^{* 2}$} \\
\hline & & $\mathrm{S}(n=1)$ & $\mathrm{J}(n=1)$ & $\mathrm{U}(n=1)$ & $\mathrm{M}(n=1)$ \\
\hline DALAD/Ls & $32.3 \pm 2.78$ & 31.5 & 32.1 & 32.4 & 31.8 \\
\hline DPDPL/Ls & $71.7 \pm 3.74$ & $62.8^{*}$ & 72.1 & 72.8 & 71.2 \\
\hline $\mathrm{HPLAA} / L \mathrm{~s}$ & $56.9 \pm 2.18$ & $44.1 *$ & 55.4 & 56.4 & 56.1 \\
\hline $\mathrm{HALAV} / L \mathrm{~s}$ & $37.5 \pm 1.16$ & 37.4 & 37.9 & 38.0 & 37.6 \\
\hline $\mathrm{HALOP} / L \mathrm{~s}$ & $21.6 \pm 0.25$ & 21.0 & 22.4 & 21.9 & 22.1 \\
\hline $\mathrm{DAAPO} / L \mathrm{~s}$ & $14.6 \pm 1.05$ & 14.8 & $16.8^{*}$ & 14.9 & 14.1 \\
\hline $\mathrm{DAUPO} / L \mathrm{~s}$ & $19.5 \pm 0.49$ & 19.4 & 19.9 & 19.4 & 20.0 \\
\hline $\mathrm{DALAD} / L \mathrm{~s}$ & $16.7 \pm 0.40$ & 16.5 & $14.1 *$ & 16.8 & 16.0 \\
\hline $\mathrm{CH} / L \mathrm{~s}$ & $5.8 \pm 0.59$ & $2.4 *$ & 5.9 & 6.1 & 5.6 \\
\hline $\mathrm{BDAA} / L \mathrm{~s}$ & $16.3 \pm 0.63$ & 17.1 & 16.4 & 16.8 & 16.1 \\
\hline $\mathrm{BDMA} / L \mathrm{~s}$ & $12.5 \pm 0.99$ & $14.3^{*}$ & 12.8 & 12.5 & 12.5 \\
\hline BDMA/BDAA & $76.5 \pm 3.16$ & $83.6^{*}$ & 78.0 & 74.4 & 77.6 \\
\hline $\mathrm{HWOP} / L \mathrm{~s}$ & $15.9 \pm 0.67$ & 15.4 & 15.9 & 16.4 & 15.6 \\
\hline HARL/HWOP & $81.1 \pm 4.28$ & 83.1 & $70.8^{*}$ & 78.5 & 81.4 \\
\hline DAHRB/DAHLB & $100.1 \pm 3.07$ & 101.1 & 98.9 & $91.1 *$ & 100.2 \\
\hline DAHRU/DAHLU & $100.4 \pm 2.91$ & 100.5 & 99.7 & $90.8^{*}$ & 100.8 \\
\hline DAHRL/DAHLL & $100.2 \pm 4.88$ & 100.7 & 100.9 & 100.1 & $101.9^{*}$ \\
\hline
\end{tabular}

${ }^{\bar{*} 1}$ For abbreviations refer to Table 1 . The values of normal group are means $\pm \mathrm{SD}(n=20)$ of triplicate groups.

${ }^{* 2} \mathrm{~S}$ : spinal curvature; J: The luxation of jawbone; U: abnormality of upper lip; and M: malocclusion. The values of asterisk mark are significantly different from the value of normal group $(P<0.05)$.

was too small (DAHLB/DAHRB: 91.1, DAHLU/DAHRU: 90.8). This catfish's left maxilla was longer than the right mandible, so it made odds.

As shown in Fig. 2, Malocclusion was seen inside of the mouth, and the head was asymmetric. Malocclusion's DHARL/DHALL was bigger than other, it means that there is no balance at jaw ( $P>0.05$; Table 5). Malocclusion does not match the balance of the left maxilla and right maxilla, and it was observed that the right maxilla is longer than the left maxilla. External shape could not be seen, but the skeletal structure saw what side of maxilla was leaned. Consequently, I saw right maxilla was leaned.

\section{DISCUSSION}

In fish, skeletal deformity was indentified with infection, physical damage, deficiency of nutrition, and development of bladder (Officer et al., 1995). It is similar to these 3 types of skeletal deformities, which re lordosis, kyphosis, and scoliosis (Hibiya, 1982).

In this study, most fatal deformity in Far Eastern catfish, Silurus asotus is accompanied by spinal curvature. There was low datas, such as the weight was low at approximately $119.6 \mathrm{~g}$ and standard length was low at about 159.8 $\mathrm{mm}$. It means that the spinal deformity delayed growth of the Far Eastern catfish. Jaw deformities didn't have odds in standard length and weight, and it means that these deformities are not fatal when eaten. GSI, his, and VI had no odds, and it means that the deformities didn't have risk regarding the gonad, liver, and intestine. Furthermore, in spinal curvature, these weights were as small as the catfish's weight. 


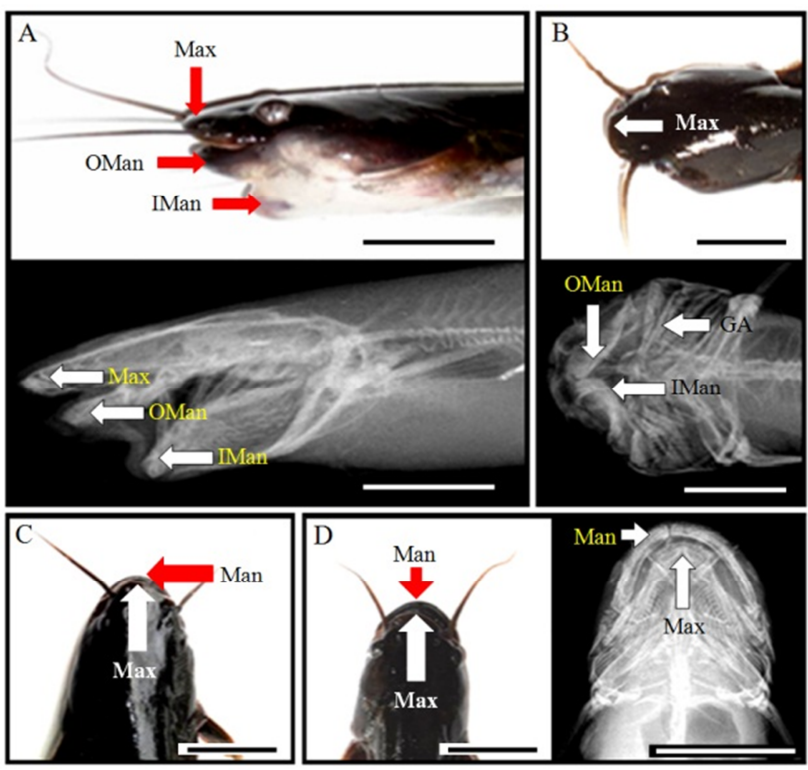

Fig. 3. The lateral and the dorsal views and $X$-ray pictures of normal and skeletal deformity group in Far Eastern catfish, Silurus asotus. A and B (upper: external morphology; lower: X-ray picture): the jawbone's luxation; C: abnormality of upper lip; and D (left: external morphology; right: X-ray picture): malocclusion. GA: gill arch; Man: mandible; Max: maxilla; IMan: inner side of mandible; and OMan: outer side of maxilla. Bars are $5 \mathrm{~cm}$.

In this study, we saw 4 deformities, which is part of all deformities. A study indicates that the deformities are mostly about appearance and skeletal deformity (Yoo et al., 2003; Fjelldal et al., 2007; Nguyen et al., 2008; Boglino et al., 2011; Haga et al., 2011). Haga et al. (2011) found the loss of caudal fin and supernumerary caudal fin rays that were observed in Japanese flounder, Paralichthys olivaceus. Changes in the morphology of fins seem to be related to stages; earlier treatment induces fin loss but it later induces supernumerary fin rays (Haga et al., 2011).

So, it is necessary to consider why deformities occur and how many types of deformities exist. The deformities are caused by environmental conditions (temperature, salinity, $\mathrm{pH}$, photoperiod, dissolved oxygen and light intensity: Lee \& Menu, 1981; Steingraeber \& Gingerich, 1991; Georgakopoulou et al., 2010). Besides, it has other causes such as diets, ions, or radioactivity (Fjelldal et al., 2007; Nguyen et al., 2008; Roo et al., 2009; Boglino et al., 2011). When vitamin A is insufficient, there is fatal risk such as in the development of skeletons (Haga et al., 2011). Furthermore, essential fatty acids are necessary to elucidate bone deformities of fish, and HUFA level leads to different effect of deformities (Roo et al., 2009). Recently, significant research activity has been focused on the nutrigenomics and proteomics approaches in fish physiology and molecular biology (Panserat \& Kaushik, 2010).

Consequently, by giving the same environmental condition and diet, deformities were identified. So, it is necessary to study why the Far Eastern catfish deformities occurs the reason for these deformities, which are likely to be caused by the increases in any condition, and ways to prevent the appearances of these deformities. Furthermore, we need to elucidate the importance of environment, diet, ions, and radioactivity. If we stand the cause of deformities, it can reduce the incidence of malformations to produce more superior Far Eastern catfish.

\section{ACKNOWLEDGEMENTS}

This research was funded through project 2010-0021293 of the National Research Foundation of Korea, Korea. And it was supported by the Fishery Genetics \& Breeding Sciences Lab., Korea Maritime and Ocean University, Korea. The comments of the anonymous reviewers greatly improved the quality of this manuscript. All experiments in this study complied with the current laws of Korea (the Law Regarding Experimental Animals, No. 9932) and the Ethical Guidelines of Korea Maritime and Ocean University, Korea.

\section{REFERENCES}

Andrades JA, Becerra J, Fernández-Llebrez P (1996) Skeletal 
deformities in larval, juvenile and adult stages of cultured gilthead sea bream (Sparus aurata L.). Aquaculture 141: $1-11$.

Ashley PJ (2007) Fish welfare: current issues in aquaculture. Appl Anim Behav Sci 104:199-235.

Boglino A, Darias MJ, Ortiz-Delgado JB, Özcan F, Estévez A, Andree KB, Hontoria F, Sarasquete C, Gisbert E (2011) Commercial products for Artemia enrichment affect growth performance, digestive system, maturation, ossifycation and incidence of skeletal deformities in Senegalese sole (Solea senegalensis) larvae. Aquaculture 325:290302.

Choi GC, Kim DS, Jo JY, Kim JM (1992) Induced breeding and indoor culture of the catfish, Silurus asotus (Telestomi: Siluridae). J Aquacult 5:117-126.

Fjelldal PG, Hansen TJ, Berg AE (2007) A radiological study on the development of vertebral deformities in cultured Atlantic salmon (Salmo salar L.). Aquaculture 273:271-728.

Gavaia PJ, Domingues S, Engrola S, Drake P, Sarasquete C, Dinis MT, Cancela ML (2009) Comparing skeletal development of wild and hatchery-reared Senegalese sole (Solea senegalensis Kaup, 1858): evaluation in larval and postlarval stages. Aquacult Res 40:1585-1593.

Georgakopoulou E, Katharios P, Divanach P, Koumoundouros G (2010) Effect of temperature on the development of skeletal deformities in gilthead sea bream (Sparus aurata Linnaeus, 1758). Aquaculture 308:13-19.

Haga Y, Du S, Satoh S, Kotani T, Fushimi H, Takeuchi T (2011) Analysis of the mechanism of skeletal deformity in fish larvae using a vitamin A-induced bone deformity model. Aquaculture 315:26-33.

Hibiya T (1982). An Atlas of Fish Histology. Kodansha LTD. pp. 27-33.

Im JH, Bang IC, Noh CH, Park I-S (2000) Induction of nitotic gynogenetic diploid in the Far Eastern catfish, Silurus asotus. J Aquacult 13:359-362.
Im JH, Cho HJ, Nam YK, Kim DS, Park I-S (2001) Production of gynogenetic diploid in the Far Eastern catfish, Silurus asotus. Gene \& Genomics 23:89-101.

Im JH, Park I-S, Jeong JH, Kim DS (2002) Karyokinesis in embryos of Far Eastern catfish, Silurus asotus. J Aquacult 15:275-277.

Imsland AK, Foss A, Koedjik R, Folkvord A, Stefansson SO, Jonassen TM (2006) Short- and long-term differences in growth, feed conversion efficiency and deformities in juvenile Atlantic cod (Gadus morhua) startfed on rotifers or zooplankton. Aquacult Res 37:1015-1027.

Kim DS, Cho HJ, Park IS, Choi GC, Nam YK (2001) Cytogenetic traits and gonad development of induced triploidy in Far Eastern catfish, Silurus asotus. Korean J Genetics 23:55-62.

Kwon AS, Kim KH, Lee YH (1998) Ultrastructure of spermatozoa in the catfish, Silurus asotus. Dev Reprod $2: 75-80$

Kwon HC, Choi NJ, Park HY (1996) Induced ovulation in catfish (Silurus asotus) by GnRH-Analogue. J Aquacult 9: 205-213.

Le Vay L, Carvalho GR, Quinitio ET, Lebata JH, Ut VN, Fushimi H (2007) Quality of hatchery-reared juveniles for marine fisheries stock enhancement. Aquaculture 268:169-180.

Lee CS, Menu B (1981) Effects of salinity on egg development and hatching in grey mullet Mugil cephalus L. J Fish Biol 19:179-188.

Lijalad M, Powell MD (2009) Effects of lower jaw deformity on swimming performance and recovery from exhaustive exercise in triploid and diploid Atlantic salmon Salmo salar L. Aquaculture 290:145-154.

Nguyen VT, Satoh S, Haga Y, Fushimi H, Kotani K (2008) Effect of zinc and manganese supplementation in Artemia on growth and vertebral deformity in red sea bream (Pagrus major) larvae. Aquaculture 285:184-192.

Officer RA, Clement JG, Rowler DK (1995) Vertebral 
deformities in a school shark, Galeorhinus galeu circumstantial evidence for endoskeletal resorption?. J Fish Biol 46:85-98.

Panserat S, Kaushik SJ (2010) Regulation of gene expression by nutritional factors in fish. Aquacult Res 41: 751-762.

Park I-S, Im JH (2001) Determination of the temperature dependent index of mitotic interval $\left(\tau_{0}\right)$ for chromosome manipulation in Far Eastern catfish, Silurus asotus. Kor J Ichthyol 13:85-88.

Park I-S, Im JH, Hur JW (2004) Morphometric characteristics of catfish (Silluridae) in Korea. Kor J Ichthyol 16:223-228.

Park I-S, Im JH, Ryu DK, Nam YK, Kim DS (2001) Effect of starvation on morphometric changes in Rhynhocypris oxycephalus (sauvage and Dabry). J Appl Ichthyol 17: 277-281.
Puvanendran V, Calder-Crewe C, Brown JA (2009) Vertebral deformity in cultured Atlantic cod larvae: ontogeny and effects on mortality. Aquacult Res 40:1653-1660.

Roo FJ, Hernández-Cruz CM, Socorro JA, FernándezPalacios H, Montero D, Izquierdo MS (2009) Effect of DHA content in rotifers on the occurrence of skeletal deformities in red porgy, Pagrus pagrus (Linnaeus, 1758). Aquaculture 287:84-93.

Steingraeber MT, Gingerich WH (1991) Hatching, growth, ion accumulation, and ossification of brook trout (Salvelinus alpinus) alevins in acidic soft waters. Can J Zool 69: 2266-2276.

Yoo JH, Takeuchi T, Jeong GS (2003) Effect of thyroid hormones and albinism during methmorphosis of flounder, Paralicthys olivaceus under low temperature stress. J Korean Fish Soc 36:65-67. 